Emerg Med J 2005;22:128-139. doi: 10.1136/emj.2004.021642

Ir he vast majority of ENT (ear, nose, and throat) problems that present in the prehospital setting are minor in nature. However, occasionally innocuous symptoms can develop into life threatening conditions that require immediate assessment and treatment.

\title{
Article objectives
}

- To undertake a primary survey of the patient and treat any immediately life threatening problems.

- To identify any patients who have a normal primary survey but have an obvious need for hospital admission.

- To undertake a secondary survey (full assessment) including history and examination targeted to the presenting symptom.

- To consider a list of differential diagnoses.

- Discuss treatment based on the probable diagnosis (es) and whether home management or hospital admission is appropriate.

- Consider need for follow up.

\section{PRIMARY SURVEY}

The primary survey is a rapid assessment tool that uses the $\mathrm{ABC}$ principles to look for an immediately life threatening condition.

\section{Box 1 Primary survey}

If any observations below are present treat immediately and transfer to hospital

- Airway obstruction

- Respiratory rate $<10$ or $>29$

- Oxygen sats $<93 \%$

- Pulse $<50$ or $>120$

- Systolic blood pressure $<90$

- Glasgow coma score $<12$

See end of article for authors' affiliations

Correspondence to:

Dr S Carter, BASICS Scotland, Auchterarder, UK;

scarter@doctors.org.uk
ENT conditions can be immediately life threatening by causing an A, B, or C problem:

- A Airway obstruction/compromise-inhaled foreign body, epiglottitis, quinsy, anaphylaxis/ angio-oedema, croup, facial fractures.

- B Breathing difficulty-croup, inhaled foreign body

- C Circulatory compromise-haemorrhage, for example, epistaxis, from facial fracture, secondary haemorrhage after ENT surgery, for example, after tonsillectomy.

\section{PATIENTS WITH A NORMAL PRIMARY SURVEY BUT WITH OBVIOUS NEED FOR HOSPITAL ADMISSION}

Patients with all of the above conditions can show a range of severity of symptoms and signs, which can deteriorate. It is essential to remember that in the early stages of these conditions, patients may not have significant abnormal physical signs. The recognition of developing airway obstruction is critical and management of the condition may require the use of airway adjuncts to maintain adequate oxygenation. If there is complete airway obstruction and airway adjuncts have failed, prompt insertion of a surgical airway may be required as a last resort. It is important to monitor patients with respiratory distress for deterioration and exhaustion. In the case of 
haemorrhage the body will initially compensate. Therefore cases leading to hypovolaemia should be treated by arresting the haemorrhage and administrating fluid to maintain a radial pulse.

The history and a brief examination may lead you to suspect that one of the above conditions is the probable diagnosis and problems with the airway, breathing, or circulation may develop. All suspected cases of:

- Foreign body inhalation

- Epiglottitis

- Anaphylaxis

- Posterior nasal haemorrhage

- Unstable facial fractures

- Secondary haemorrhage after surgery

should be admitted to hospital for further investigation and management. However, not all cases of croup or epistaxis will require hospital admission. Management of the individual conditions will be discussed below or in other articles in the series.

\section{SECONDARY SURVEY}

Patients still remaining after the primary survey require a thorough assessment to determine optimal treatment and discharge (see article 2 in the series).

\section{History and examination}

This should be targeted to the presenting symptom and associated systems. Examination of the respiratory and cardiovascular systems is always necessary. This should be supplemented with abdominal assessment when glandular fever is suspected looking for hepatosplenomegaly and examination of the central nervous system if vertigo or facial weakness is the presenting symptom.

\section{Vital signs}

Unless you are transporting the patient immediately, then always measure a full set of vital signs.

\section{Investigations}

Other than a full history and examination there are no investigations available in the prehospital setting able to confirm or refute any of the differential diagnoses.

\section{DIFFERENTIAL DIAGNOSIS}

Table 1 is a list of the differential diagnoses classified by presenting symptom.

\section{PRESENTING SYMPTOMS HISTORY, EXAMINATION AND TREATMENT NOSEBLEED}

The following points in the history are important for the management of a patient with a nosebleed.

- Age of patient?

- Number of bleeding episodes?

- Sensation of blood in the throat?

- Amount of blood/duration of bleeding?

- History of epistaxis, trauma, nasal surgery?

- Family history of bleeding disorder?

- Anticoagulant, NSAID, aspirin, cocaine use?

- Other significant medical conditions, for example ischaemic heart disease, COPD, hypertension, coagulopathy? When examining the patient try to locate the side of the bleeding, look at the linearity of the nose (if asymmetrical is

\begin{tabular}{|c|c|c|}
\hline Presenting symptom & ENT diagnoses & Other differential diagnoses \\
\hline Nosebleed & $\begin{array}{l}\text { Anterior bleed } \\
\text { Posterior bleed } \\
\text { Traumatic } \\
\text { After surgery }\end{array}$ & Underlying bleeding disorder \\
\hline Sore throat & $\begin{array}{l}\text { Tonsillitis } \\
\text { Pharyngitis } \\
\text { Glandular fever } \\
\text { Candida } \\
\text { Quinsy } \\
\text { Stevens Johnson syndrome } \\
\text { Ramsey Hunt syndrome }\end{array}$ & $\begin{array}{l}\text { Angina } \\
\text { Gastro-oesophageal reflux } \\
\text { Tobacco use } \\
\text { Occupational irritants }\end{array}$ \\
\hline Sore ears & $\begin{array}{l}\text { Otitis externa } \\
\text { Viral otitis media } \\
\text { Bacterial otitis media } \\
\text { Perforated tympanic membrane } \\
\text { Eustation tube dysfunction } \\
\text { Mastoiditis } \\
\text { Ramsey Hunt syndrome }\end{array}$ & $\begin{array}{l}\text { Tempromandibular joint dysfunction } \\
\text { Upper gastrointestingal and airway neoplasms } \\
\text { Dental } \\
\text { Cervical spondylosis }\end{array}$ \\
\hline Foreign body & $\begin{array}{l}\text { Ears } \\
\text { Nose }\end{array}$ & \\
\hline $\begin{array}{l}\text { Difficult/noisy } \\
\text { breathing }\end{array}$ & $\begin{array}{l}\text { Foreign body } \\
\text { Epiglotitis } \\
\text { Croup } \\
\text { Anaphylaxis } \\
\text { Bacterial tracheitis }\end{array}$ & $\begin{array}{l}\text { Asthma } \\
\text { COPD }\end{array}$ \\
\hline Vertigo & $\begin{array}{l}\text { Vestibular neuronitis } \\
\text { Menieres } \\
\text { Benign paroxysmal positional vertigo }\end{array}$ & $\begin{array}{l}\text { Cerebellar CVA } \\
\text { Other central causes }\end{array}$ \\
\hline Facial/tooth pain & $\begin{array}{l}\text { Sinusitis } \\
\text { Dental abscess }\end{array}$ & $\begin{array}{l}\text { Shingles } \\
\text { Trigeminal neuralgia }\end{array}$ \\
\hline Facial weakness & $\begin{array}{l}\text { Bells palsy } \\
\text { Ramsey Hunt syndrome }\end{array}$ & Cerebrovascular accident \\
\hline Sudden hearing loss & $\begin{array}{l}\text { Wax impaction } \\
\text { Perforated TM }\end{array}$ & Cerebrovascular accident \\
\hline Trauma & $\begin{array}{l}\text { Facial fractures } \\
\text { Perforated TM }\end{array}$ & \\
\hline
\end{tabular}


this attributable to recent trauma); check the appearance of the septum and Little's area. The latter is the area of the septum seen through the nostrils when the nasal tip is tilted upwards (fig 1). Blood vessels in Little's area are prone to bleeding. Check the throat for blood running down the nasopharynx. Ensure you get a set of vital signs and examine the cardiovascular system looking for any indication of shock.

The treatment of epistaxis is dependent on the site of the bleeding and the experience of the healthcare professional.

\section{Box 2 Healthcare professionals with additional} skills

If the bleeding point can be visualised cautery of the vessel can be attempted with either silver nitrate or electrocautery if available. Cautery should be applied to a specific vessel and not used in a blanket fashion to the nasal mucosa. If the bleeding source is not visible, or cautery fails, then the nose should be packed with an anterior pack.

\section{栕 Tip}

Most nosebleeds will respond to simple first aid measures of compression and cooling. It is important to note that effective compression occludes both nostrils without release, for 20 minutes. Cooling with a cold compress over the forehead and bridge of the nose can also be effective by causing vasoconstriction of the nasal vessels.

If bleeding has stopped by the time of presentation or ceases with the simple first aid measures above, and the vital signs are normal no further treatment is necessary. If it is a recurrent bleed antibiotic nasal cream should be prescribed. Recurrent nosebleeds in children tend to be caused by digital trauma to Little's area. In adults remember to check blood pressure. If raised, ask them to attend their GP for further management.

If the bleeding fails to respond to simple first aid measures packing should be applied to the nasal cavity from which the bleed is suspected to have originated. The simplest pack and the easiest to insert is the nasal tampon (fig 2). However, the nose can be packed with ribbon gauze if available and the healthcare professional is competent at the procedure. Nasal tampons are supplied small and flat but expand and take on the contours of the cavity when they are hydrated with either blood or saline. The leading edge of the nasal tampon should

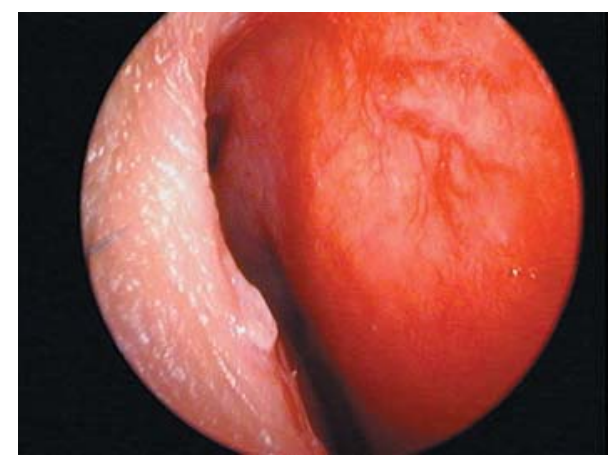

Figure 1 Little's area of the nasal septum. (Courtesy of Mr Kim Ah-See ENT consultant, Aberdeen).

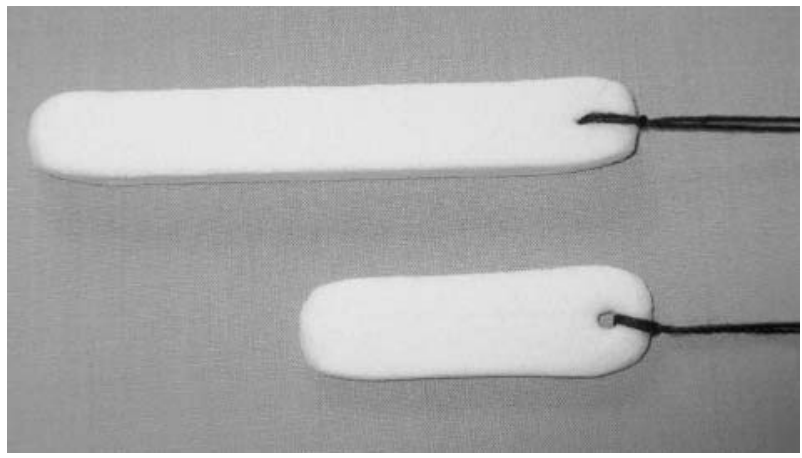

Figure 2 Nasal tampon.

be lubricated before insertion. It should then be inserted in a horizontal plane into the nasal cavity (fig 3). If the nasal tampon does not expand with the blood in the nose, saline should be dripped onto the external end of the nasal tampon until it expands and causes compression. The thread of the tampon should be secured with tape and a nasal sling may be applied to soak up any excess blood.

If anterior packing fails to stop the bleeding after 15 minutes a posterior bleed should be suspected (about $5 \%$ of bleeds). These require packing using a long nasal tampon, an epistaxis balloon, or a Foley catheter with an anterior pack depending what is available (fig 4). Long (posterior) nasal tampons are inserted in the same way as an anterior tampon. Some epistaxis balloons have an anterior and posterior balloon. The balloon is lubricated with saline and inserted, again in a horizontal plane. The posterior balloon is inflated to the recommended volume, gentle traction is applied to position the balloon in the posterior nasal space, and then the anterior balloon is inflated to the recommended volume. Foley catheters and single balloon epistaxis catheters are inserted in the same way but do not have an anterior balloon and therefore an anterior pack is necessary. The Foley catheter must be secured with care taken to prevent pressure necrosis of the nasal tissues. All

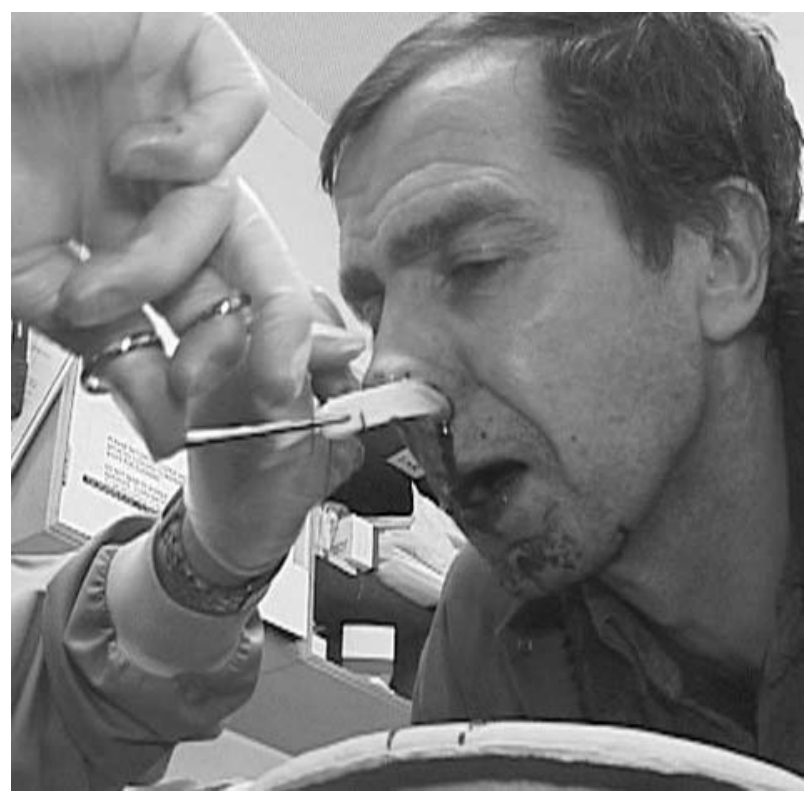

Figure 3 Nasal tampon insertion. 
Box 3 Patients with a nosebleed-who needs to go to hospital?

- All patients with a posterior pack must be admitted to hospital. They require analgesia and close monitoring particularly of vital signs and oxygen saturations.

- All patients with a personal history of bleeding disorder must be admitted to hospital.

- Patients with a history of recent nasal surgery should be discussed with the appropriate surgical team.

- Patients taking anticoagulants may be treated in the community if a recent INR is known and over anticoagulation is not suspected.

- Patients with an anterior pack and significant other medical illness such as angina or COPD should be considered for admission for close monitoring depending on severity of comorbid conditions. By packing the patient's nose we cause respiratory compromise that may lead to exacerbations of pre-existing illnesses.

- Epistaxis precipitated by trauma and where a facial or nasal fracture cannot be excluded should be referred to hospital.

patients with a posterior bleed require admission. If a large volume of blood has been lost oxygen, venous access and fluid resuscitation may be necessary.

\section{SORE THROAT}

Several features need to be elicited when dealing with patients with sore throats:

- Duration

- Previous episodes or recent surgery?

- Response to previous treatments?

- One side or both?

- Associated features or other symptoms? Associated symptoms may lead to a particular diagnosis.

- Ability to swallow food, liquid, saliva?

- Hallitosis?

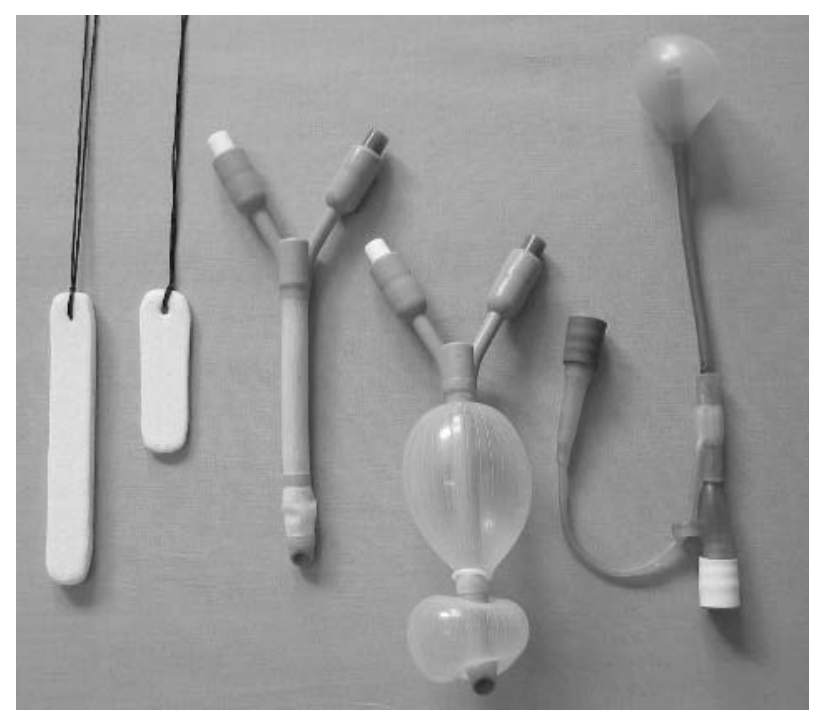

Figure 4 Posterior and anterior nasal tampons, deflated and inflated double balloon epistaxis catheters, and single posterior space epistaxis balloon catheter.
- Drugs that may cause agranulocytosis, candidal overgrowth or Stevens Johnson syndrome?

- Occupational exposure to physical irritants?

When examining the throat look at the appearance of the tonsils and surrounding tissue. If swelling is present is it bilateral or unilateral. Is there pus or exudate present on the tonsils (tonsillitis or glandular fever)? If the patient has had recent tonsilar surgery does the tonsilar bed look sloughy, infected, or bleeding. Is there peritonsilar redness or swelling (peritonsilar cellulitis)? Look at the appearance of the pharynx, does it look red (pharyngitis), are there any white spots (candida) or ulcerated areas. Can the patient swallow or are they drooling saliva. Is trismus (spasm of the pterygoid muscles preventing opening of the mouth) present (quinsy)? Does the patient have features of systemic toxicity or lymph nodes?

\section{Pharyngitis/tonsillitis/glandular fever/candida}

Most sore throats (90\%-95\%) are viral in nature and require only symptomatic treatment with fluids and an antipyretic analgesic. Mild cases of bacterial tonsillitis, commonly streptococci, will also respond to this conservative treatment. However, if the patient has significant fever, nausea and vomiting, and no signs of a viral upper respiratory tract infection the use of antibiotics can be argued. The choice of antibiotic should be penicillin $\mathrm{V}$ or erythromycin initially for 10 days. Shorter treatment durations have been associated with recurrent and early relapse of the infection. There is no test available to differentiate glandular fever from tonsillitis at initial emergency presentation. Therefore the initial treatment is the same as for tonsillitis. Amoxicillin based antibiotics should be avoided if glandular fever is suspected as it can cause a generalised macular rash. If the patient is unable to swallow fluids or their own saliva hospital admission for assessment and intravenous antibiotics will be necessary. Candidal sore throats can be suspected on history and confirmed on examination by the presence of white plaques adherent to the mucosa of the palate and gums (fig 5). Treatment is with a topical antifungal such as nystatin. If the patient is immunocompromised then systemic antifungals may be necessary.

\section{Peritonsilar cellulitis and quinsy}

Both of these conditions are complications of bacterial tonsillitis and should be suspected in someone whose sore throat gets substantially worse and they become more unwell than is usual with an uncomplicated tonsillitis. Peritonsillar cellulitis is the presuppurative stage of quinsy-a localised collection of pus above the tonsil. A patient with either condition will complain of a severe unilateral sore throat and difficulty

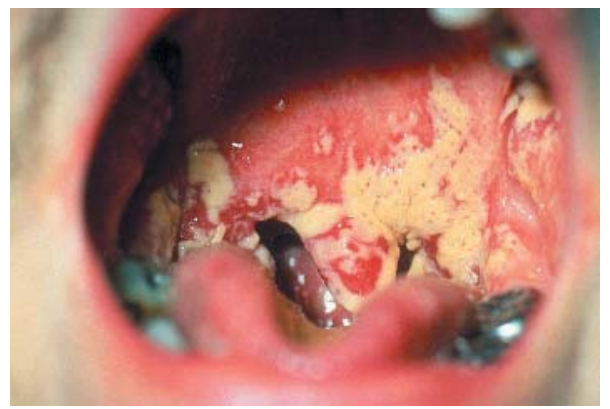

Figure 5 Candidal infection of throat. 
swallowing. The patient may also complain of ipsilateral (on the same side) ear pain and pain on movement of the neck. Examination of the throat will reveal a very swollen, red area above and to the side of the inflamed tonsil. The uvula (the tissue that hangs down from the roof of the mouth at the back of the palate) may be pushed to one side. Enlarged cervical lymph nodes are the cause of the neck pain. If peritonsilar cellulitis is the diagnosis there will be comparatively little trismus. If trismus is a feature quinsy should be suspected. There may be a change to the quality of the voice. Treatment may require drainage, intravenous antibiotics, and fluids. Suspected cases need to be referred to hospital for assessment and treatment.

\section{Stevens Johnson syndrome}

This is a rare multisystem illness with widespread vesiculobullous lesions and erosions of the mucous membranes associated with erythema multiforme of the skin (fig 6). The highest incidence is in the 20-40 year age group, it is twice as common in males, and is more common in spring and autumn. Infection, especially mycoplasma and herpes simplex, drugs, especially antibiotics and anticonvulsants, and malignancies are common precipitating factors. Fifty per cent of cases have no identifiable aetiology. Suspected cases should be referred to hospital for assessment as many will require intensive care unit or high dependency unit care.

\section{Ramsey Hunt syndrome}

See below.

\section{Non-ENT causes of sore throat}

Angina can present with pain in the throat or jaw related to physical exertion. Consider this in middle aged and older patients, with or without a history of ischaemic heart disease, with a normal throat examination, and no other ENT symptoms. Patients with suspected angina should have an ECG and be given sublingual nitrate. See chest pain article in this series.

Gastro-oesophageal reflux disease can present with a sore throat and persistent cough. Examination often shows pharyngitis. Consider this in older, overweight patients with a persistent sore throat with or without a history of dyspepsia.

Tobacco use-heavy smokers may develop a chronic pharyngitis with pain.

Occupational irritants-fumes from some chemicals can cause a chronic pharyngitis.

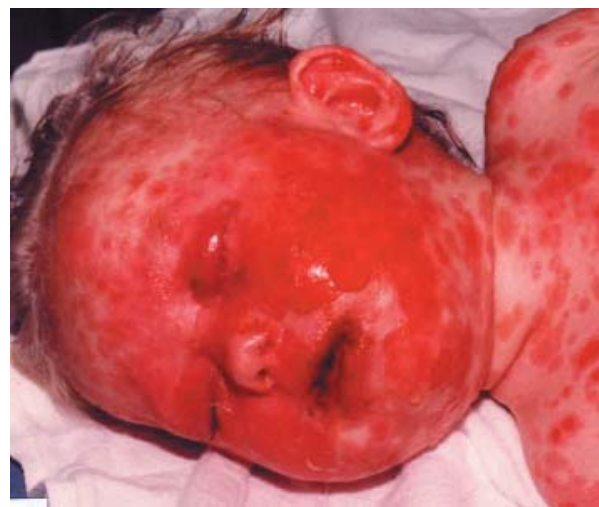

Figure 6 Stevens Johnson syndrome.
Box 4 Patients with a sore throat-who needs to go to hospital?

- Patients with severe tonsillitis with systemic upset and inability to swallow should be admitted for intravenous antibiotics and fluid. Pain on swallowing, on its own, is not an indication for hospital admission.

- Patients with quinsy should be admitted to hospital for incision and drainage.

- Patients with suspected Stevens Johnson syndrome should be admitted to hospital.

See sore throat flow chart (fig 7).

\section{SORE EARS/DISCHARGING EARS}

Painful ears are a common complaint particularly in young children. The pain may originate from the ear itself or be referred from another site. There are some important features to establish about the pain to help make the diagnosis.

- Is there a discharge?

- Associated symptoms, for example, coryza, symptoms of systemic toxicity

- One ear or both?

- Previous episodes, previous surgery, or recent ear syringing?

- Do you use cotton buds?

- Recent swimming, diving, or flying?

- Is there any associated hearing loss?

When examining the ear look: for the presence of scars; for deformity of pinna; at the appearance of external auditory canals; at the appearance of tympanic membranes. Feel for lymph nodes. Does tugging on the pinna (fig 8) or pressure on the tragus cause discomfort (otitis externa/furunculosis): look behind the pinna at the skin over the mastoid process for swelling or redness feel for tenderness (mastoiditis).

\section{领 Tip}

Always examine the non-painful ear first.

\section{Otitis externa/furunculosis}

Otitis externa is an inflammation (usually infective) of the external auditory canal, which can spread to the pinna, periauricular soft tissues, or even the temporal bone. It is common in patients with eczematous ear canal skin and in those who produce trauma with cotton buds. Streptococci, staphylococci, pseudomonas, and fungi are the usual infecting organisms. Pressure on the tragus or gentle tugging on the pinna (fig 8) will cause discomfort. In the early stages the canal is tender and red and there may be a slight watery discharge. As the condition progresses there may be oedema of the canal and accumulation of debris. Treatment is with topical antibiotic and corticosteroid combination drops and simple analgesia. Any associated cellulitis should be treated with systemic antibiotics.

Furunculosis is an infection of a hair follicle. When this occurs in the outer ear canal it causes severe throbbing pain. Examination of the ear canal may disclose a red lump with or without puss. The abscess may rupture itself or may in severe cases require incision and drainage. Simple analgesia is the only initial treatment necessary with advice to see the GP if not improving within 48 hours. 


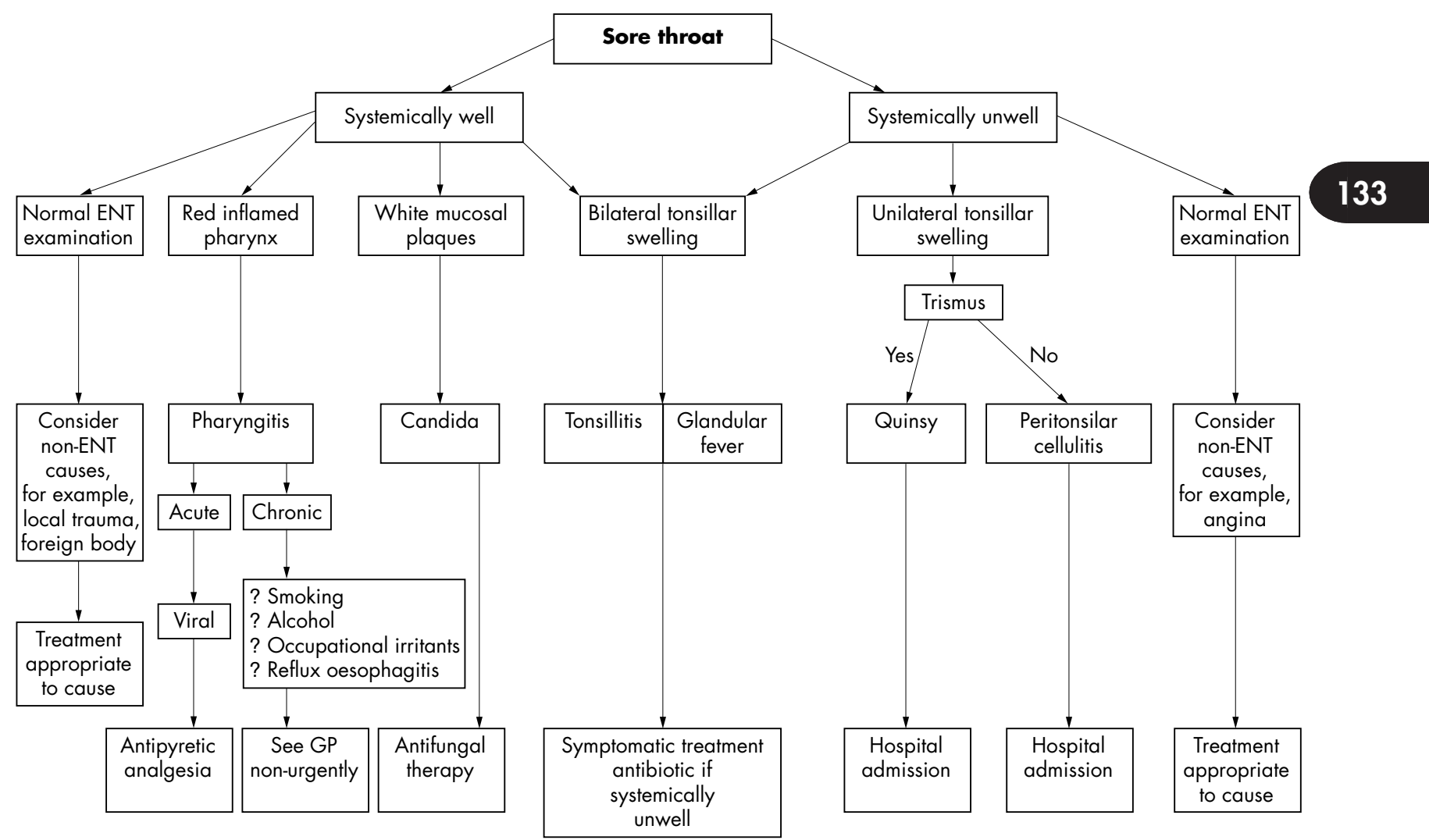

Safety net by telling patient to seek further advice or follow up by GP if symptoms worsen or symptoms fail to resolve

Figure 7 Sore throat flow chart.

\section{Otitis media' 2}

Acute otitis media is usually a short term inflammation of the middle ear and is principally characterised by ear ache,

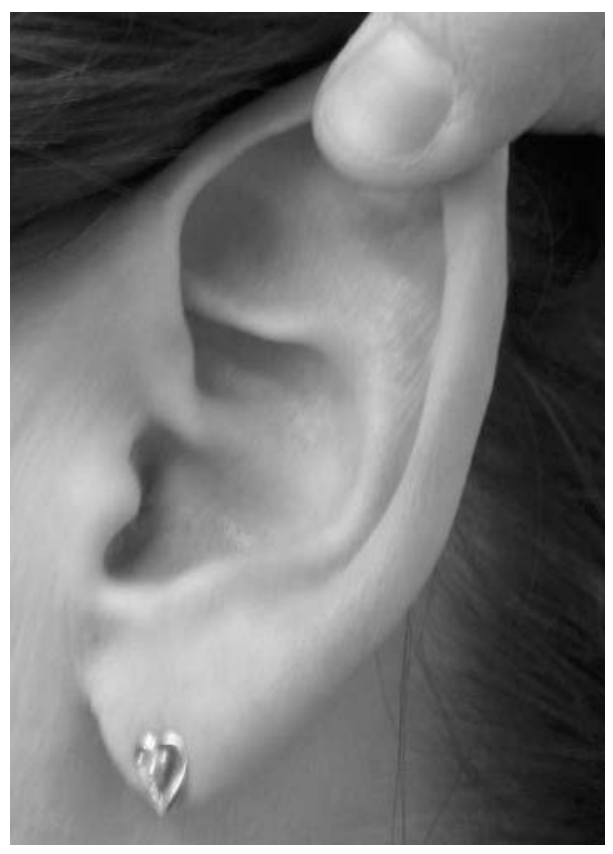

Figure 8 Tugging on pinna in an upward and backward direction to try and elicit discomfort caused by external auditory canal problems. irritability, and ear tugging in children. Loss of hearing may also occur because of effusion in the middle ear. It is often preceded by upper respiratory symptoms, including cough and rhinorrhoea. Systemic symptoms can also be present depending on the severity of the illness. Otoscopic appearances typical of acute otits media include bulging tympanic membrane with loss of landmarks, changes in membrane colour (typically red or yellow), and perforated tympanic membrane with discharge of pus. The cause of acute otitis media may be viral or bacterial in origin. Viruses are present in about $40 \%-75 \%$ of infections and often precede or coexist with bacterial infections. The main bacteria responsible are Streptococcus pneumoniae (40\%), Haemophilus influenzae (25\%), and Moraxella cattarhalis (10\%). Effusion is a common complication of acute otitis media but severe complications including mastoiditis are exceedingly rare. Mastoiditis has been found to occur in less than 1 in 1000 children with untreated acute otitis media.

Acute otitis media is usually a self limiting condition. About $80 \%$ of acute otitis media will resolve within three days without antibiotic treatment. Although there is no definitive consensus on the optimum treatment of acute otitis media in children the available evidence suggests that antibiotic treatment should not be offered routinely. The mainstay of treatment is analgesia. Both paracetamol and ibuprofen are adequate analgesics. Parents should be reassured and involved in discussions of the pros and cons of antibiotic treatment. A "wait and see" approach may be a good compromise for some people. A prescription for antibiotics can be 
Table 2 Recommended antibiotics for uncomplicated otitis media

\begin{tabular}{|c|c|c|}
\hline Antibiotic treatment & Acute otitis media first line & $\begin{array}{l}\text { Acute otitis media second line } \\
\text { (treatment failure) }\end{array}$ \\
\hline No penicillin allergy & Amoxycillin & Co-amoxiclav \\
\hline Penicillin allergy & $\begin{array}{l}\text { Azithromycin } \\
\text { Erythromycin } \\
\text { Clarithromycin }\end{array}$ & $\begin{array}{l}\text { Azithromycin if erythromycin used first } \\
\text { line or seek specialist advice from local }\end{array}$ \\
\hline
\end{tabular}

issued on the day of consultation but not be redeemed unless the condition has not resolved after 72 hours. This has been found to be effective and feasible in two studies. ${ }^{3}{ }^{4}$ Although antibiotics should not be routinely prescribed, the following indications may support their selective use; child under 2 years, bilateral acute otitis media, systemic symptoms including high temperature and vomiting, local signs (such as tympanic perforation and discharge of pus) that suggest the infection is severe. Table 2 shows the recommended antibiotics for uncomplicated acute otitis media.

There is currently no consensus on the optimal length of treatment with antibiotics for acute otitis media but the available evidence suggests that a five day course of antibiotics is usually adequate with the exception of azithromycin where three days use is sufficient because of its unique pharmacokinetics. The treatment of acute otitis media with antihistamines and decongestants is not recommended. (Additional information on antibiotic treatment for acute otitis media is available on line (http://www.emjonline. com/supplmental).

\section{Perforated tympanic membrane}

Tympanic perforations may be secondary to acute otitis media or trauma. Examination of the ear shows loss of the cone of light as the light usually reflects off the tympanic membrane. Perforations may be partial or total. Partial perforations are easier to recognise than total perforations. Those associated with acute otitis media and profuse discharge of pus should be treated with antibiotics. Traumatic perforations do not require initial treatment. All patients with perforations should be told not to put anything in the ear and not to submerge the ear under water. Not all perforations will heal therefore follow up by the GP 10-14 days later is required or sooner if new symptoms develop.

\section{Mastoiditis}

This is a complication of acute otitis media. Presentation is usually of severe pain over the mastoid process and the patient being systemically unwell. Early signs include oedema and redness over the mastoid and oedema of the posterior ear canal wall, which is seen as a bulging or sagging of the posterior wall as you look into the external auditory meatus. In severe cases the pinna can be pushed forward. This condition must be referred to hospital for treatment.

\section{Ramsey Hunt syndrome}

Herpes zoster infection of the motor ganglia of the 7th cranial nerve (facial nerve) produces a facial nerve palsy associated with the typical shingles rash in the ear and often on the soft palate and loss of taste on the anterior two thirds of the tongue. Patients with this condition must be discussed with a senior ENT surgeon or referred back to their own GP if symptoms are not severe.

\section{Non-ENT causes of ear pain}

If there is nothing to find on physical examination of the ear the pain may be referred. There are no causes that need out of hours' treatment but the patient requires simple analgesia and told to see their own GP for further assessment.

\section{FOREIGN BODY}

Foreign bodies in the nose and ear are common in children. A foreign body in the nose, unless impacted, may be inhaled and cause airway compromise. The best way of removal from the nose is to encourage the patient to blow it out themselves, although this can be very difficult in children. An alternative is to cause pressure behind the object to dislodge it. This can be done either by the parent blowing into the child's mouth while occluding the unaffected nostril or by using a bagvalve-mask to produce the pressure. The swift puff of air forces the foreign body down the nostril. If this does not work and there is a risk of inhalation further assistance should be sought. Foreign bodies in ears are not such a potential problem and routine attendance to GP or accident and emergency is sufficient advice.

\section{DIFFICULT/NOISY BREATHING}

Table 3 shows causes of difficult/noisy breathing.

\section{Epiglottitis}

This is a life threatening condition caused by Haemophilus influenzae infection of the epiglottis. It is now much less common since the advent of Hib vaccination but can occur in those who have not been immunised. Although usually seen in 3-7 year olds it can occur in adults. The onset of symptoms is rapid with high fever and sore throat being the earliest features. The patient can then develop stridor (a harsh, high pitched, musical sound produced by turbulent airflow through a partially obstructed airway) and the voice may be muffled or absent. Tacycardia, tachypnoea, swallowing difficulties, and drooling may then ensue. The patient will appear toxic, apprehensive, and pale. Often they sit upright, leaning forward with neck extended, mouth open and jaw thrust forward-in an attempt to maximise the diameter of the airway. There is usually no cough. Cyanosis, shock, loss of consciousness, and complete airway obstruction will ensue unless intervention by a senior ENT surgeon is instigated immediately. Do not attempt to examine the throat. Refer immediately to a hospital with ENT facilities and warn of suspected diagnosis. Give oxygen but do not cause distress to the child and allow the patient to maintain their upright posture. Be prepared to manage the airway on route if necessary. Continue to reassess $\mathrm{ABCs}$ during transfer.

\section{Croup}

Laryngotracheobronchitis is usually a viral infection. It may be mild or severe and the child can quickly develop respiratory distress. Occurring mainly between age of 6 months and 3 years you should suspect if there is fever, a painful 


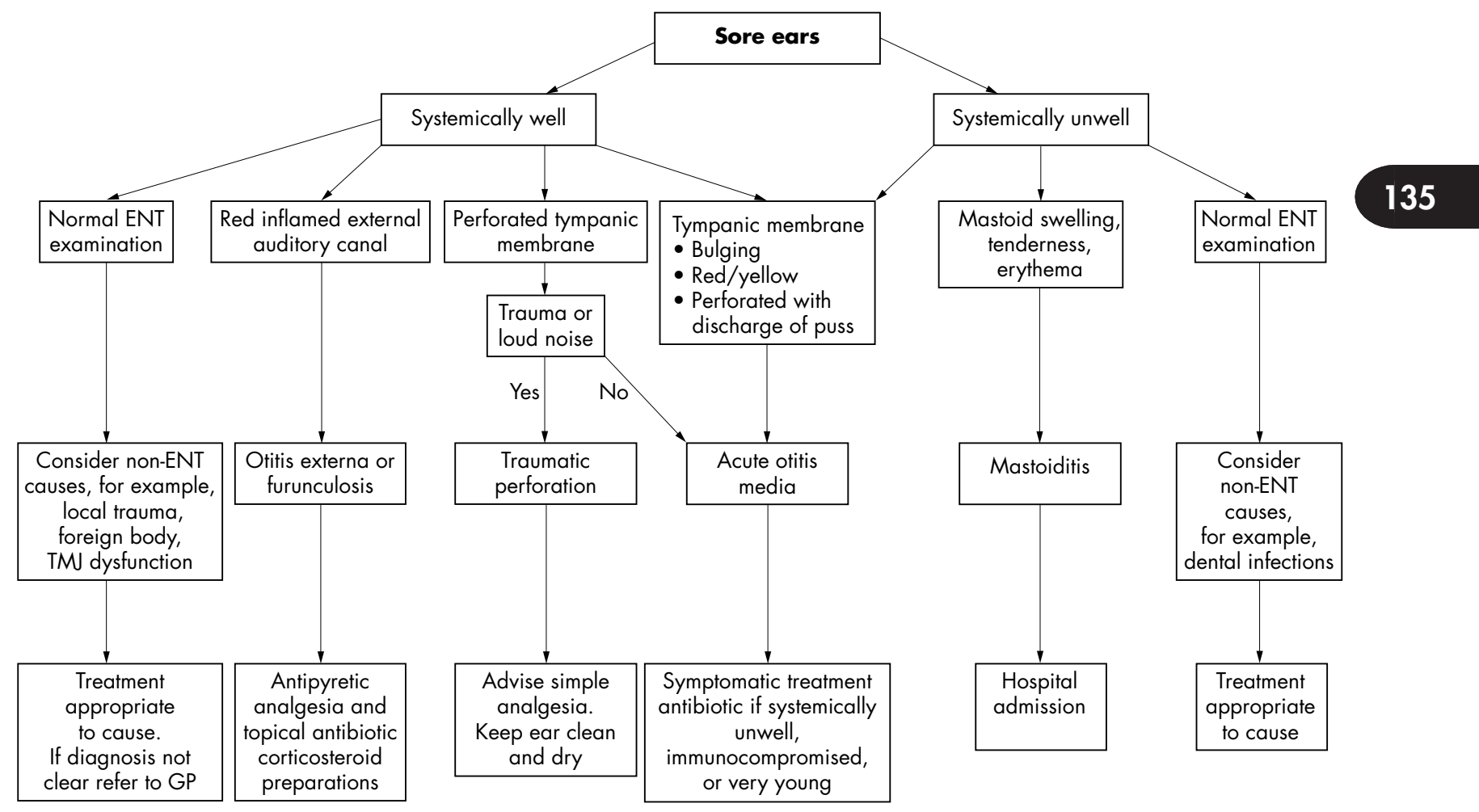

Safety net by telling patient to seek further advice or follow up by GP if symptoms worsen or symptoms fail to resolve

Figure 9 Sore ear flow chart.

barking cough, and stridor. All children under the age of 1 year should be admitted to hospital. If there are features of severe respiratory distress (box 5 ) the child should be admitted to hospital irrespective of age.

Cortiocosteroid treatment should be started if not admitting the child. A single dose of soluble prednisolone $20 \mathrm{mg}$ or alternative can be given. The child should be reassessed two to four later to ensure the stridor is not worsening. If there is severe airway obstruction nebulised adrenaline (epinephrine) ( $5 \mathrm{ml}$ of $1: 10000$ or $1 \mathrm{ml}$ of $1: 1000$ diluted to $5 \mathrm{ml}$ with saline) can be given and rapid transport arranged. Severe respiratory distress can come on quickly and the healthcare professional should be prepared to intubate and ventilate in the case of respiratory arrest.

\section{Box 5 Features of severe respiratory distress}

- Cyanosis

- Agitation

- Extreme dyspnoea

- $\mathrm{SpO}_{2}<93 \%$ in air

- Pronounced use of accessory muscles with pronounced intercostal and subcostal recession and fatigue.

\section{Bacterial tracheitis}

Stridor, hoarse voice, and cough associated with a high fever and a toxic ill looking child without swallowing difficulties suggests bacterial tracheitis. These children should be admitted to hospital.

Table 3 Causes and symptoms of difficult/noisy breathing.

\begin{tabular}{|c|c|c|c|c|c|c|}
\hline & Epiglotittis & Croup & $\begin{array}{l}\text { Bacterial } \\
\text { tracheitis }\end{array}$ & $\begin{array}{l}\text { Foreign body } \\
\text { inhalation }\end{array}$ & $\begin{array}{l}\text { Smoke } \\
\text { inhalation }\end{array}$ & Asthma \\
\hline Age group & $\begin{array}{l}3 \text { to } 7 \text { years } \\
\text { commonest }\end{array}$ & $\begin{array}{l}6 \text { months to } \\
3 \text { years }\end{array}$ & Any & Any & Any & Any \\
\hline III/systemic toxicity & Yes & No & Yes & No & No & No \\
\hline Fever & Yes & Yes/no & Yes & No & No & No \\
\hline Sudden onset & Yes & No & No & Yes & History of contact & Yes/no \\
\hline Cough & Unlikely & Yes & Yes & Yes/no & Yes/no & Yes/no \\
\hline Stridor & Yes & Yes & Yes & Yes/no & Yes/no & No \\
\hline Sore throat & Yes & Yes/no & Yes/no & No & No & No \\
\hline Changed voice & Yes & No & Yes & No & Yes/no & No \\
\hline Drooling & Yes & No & No & Yes/no & No & No \\
\hline
\end{tabular}


Table 4 Symptoms and causes of vertigo

\begin{tabular}{ll}
\hline Peripheral vestibular disorder & Central vestibular disorder \\
\hline Nystagmus & Nystagmus \\
Horizontal with a tortional componant & Gaze evoked \\
Increase in intensity when gaze to side of fast phase & Horizontal, vertical, or tortional \\
Nystagmus can be controlled by fixation & Nystagmus cannot be controlled by fixation \\
Normal CNS examination & May be: \\
Unsteady gait lean or fall to side opposite & Cranial nerve signs \\
the fast phase of nystagmus & Cerebellar signs \\
& Motor weakness \\
& Other CNS disturbance \\
& May be unable to walk without falling \\
\hline
\end{tabular}

\section{Smoke inhalation}

Smoke inhalation may be mild, moderate, or severe. If associated with other injuries the patient should be sent to hospital for a full assessment. The signs and symptoms of injury may not be immediately apparent but suspect an airway burn and the potential for the patient to develop airway obstruction if the patient has singed eyebrows and singed nasal hair. The important signs to look for are increased respiratory rate, hoarseness, stridor, and carbonaceous sputum. If any of these are present give 100\% oxygen and arrange transfer to hospital for further assessment.

\section{Non-ENT causes of difficult/noisy breathing}

Asthma and COPD are covered in the article on breathlessness.

\section{VERTIGO}

Vertigo, an illusion of movement, is the cardinal symptom of vestibular dysfunction. Vertigo is typically rotational, but it can be an illusion of tilting to one side or swaying. It is common for acute vertigo to cause a feeling of imbalance during standing or walking. Patients want to lie still and avoid movement. Acute vertigo is accompanied by nausea, vomiting, and autonomic distress of varying degrees of severity. The difficulty is separating the peripheral (otogenic) causes from a central cause. Peripheral conditions causing vertigo can include external auditory canal obstruction, middle ear infection or trauma, Meniere's disease, and vestibular neuronitis. Central problems presenting with vertigo are usually more serious than the peripheral ones and can include cerebellar infarct or haemorrhage, intracranial space occupying lesions, and demyelinating disease.

Some additional questions in the history may help.

- Duration of the vertigo and rate of onset?

- Associated hearing loss and or tinnitus?

- Is the vertigo precipitated by rapid head movement?

- Any previous ear problems, trauma, or surgery?

A detailed examination of the ear and central nervous system (particularly looking for cerebellar signs) is required. The type of nystagmus, presence of cerebellar or other neurological symptoms or signs, presence of risk factors for stroke, and ability of the patient to walk may help to reach a diagnosis (see table 4).

\section{Ménière's syndrome}

Patients with Meniere's syndrome occasionally present with an isolated episode of severe vertigo that lasts for hours and is followed by a sensation of unsteadiness and dizziness for days. Typically, however, the vertigo is preceded or accompanied by reduced hearing, tinnitus that changes in pitch in association with the episode, and a sense of fullness or blocking of the ear. Over time, the episodes of Meniere's syndrome recur, and fluctuations in hearing and episodes of tinnitus may be followed by a residual, low frequency, sensorineural hearing loss. Fluctuating hearing levels associated with recurrent episodes of vertigo are central to the diagnosis of Meniere's syndrome. Examination of the ear may show deafness but ENT examination is otherwise normal and CNS examination is normal.

\section{Vestibular neuronitis}

This is a clinical syndrome characterised by the acute onset of rotatory vertigo, which is associated with spontaneous nystagmus, postural imbalance, and nausea without accompanying cochlear or neurological symptoms. It typically begins over a period of a few hours, peaks in the first day, and then improves within days. Disabling vertigo usually resolves within a week, but it may be followed by a sensation of unsteadiness or transient episodes of dizziness. Complete recovery from the symptoms usually occurs within weeks to months.

\section{Benign paroxysmal positional vertigo}

This the commonest cause of vertigo. The classic symptoms include vertigo that appears with a few seconds latency when changing position of the head in space. The vertigo fades in 30-60 seconds. The dizziness is combined with a nystagmus beating in the direction of the affected cannal. The condition is caused by debris in the semicircular canals.

\section{Cerebrovascular event}

Cerebellar transient ischaemic episodes or cerebrovascular accidents can present with vertigo. Symptoms are usually sudden onset and associated with nystagmus, ataxia, and subtle coordination problems. Other neurological manifestations may or may not be present. Coordination can be assessed using the finger-nose test, hand tapping, and heelshin test. Hearing loss and tinitus tend not to be features and examination of the ear is normal. Patients with an acute cerebellar stroke are often unable to walk without falling. Current recommendations are that all patients with suspected transient ischaemic attack or cerebrovascular accident are admitted to hospital for further investigation and treatment. However, unless the vertigo is particularly disabling or there are social reasons admission can be delayed if there is diagnostic uncertainty. If a decision is made not to admit, the patient will require to see a GP within 24 hours.

Other central causes usually present insidiously. 


\section{Cerebellar examination Nystagmus}

Assess for nystagmus, a rhythmical beating/flickering of the eye on movement of the eye. Nystagmus at extremes of gaze is not abnormal. Peripheral vestibular nystagmus continues in the same direction when the direction of gaze changes. The direction is typically horizontal, with a tortional (rotational) component and increases in intensity when the gaze is in the direction of the fast phase, and decreases in intensity when the gaze is away from the fast phase (Alexander's law). The intensity and the velocity of its slow phase are attenuated by visual fixation and increased by removing fixation acute central disorders, such as infarction or haemorrhage of the brain stem or the cerebellum, may cause spontaneous nystagmus that changes its direction with a change in the direction of gaze (gaze evoked nystagmus). However, in patients with cerebellar stroke, nystagmus may be present only when the patient is gazing in one direction, thereby appearing similar to a peripheral vestibular nystagmus. Purely vertical nystagmus (nystagmus on looking up and down) and purely torsional nystagmus are almost always attributable to a central disorder, whereas horizontal and torsional components may occur simultaneously in patients with either peripheral or central disorders. Visual fixation may have little effect on the intensity of central vestibular nystagmus

\section{Gait ataxia}

When trying to walk the patient is unsteady often repeatedly stumbling to the same side. To detect a more subtle disturbance of cerebellar function ask the patient to heeltoe walk. Remember however that the patient if elderly may already have a gait disturbance or loss of confidence.

\section{Coordination tests}

Always remember to assess one side against the other and not in relation to yourself. For ease of explanation show the patient what you want them to do.

Finger-nose test-ask the patient to touch their nose with a single finger then to touch your finger held about $0.5 \mathrm{~m}$ in front of them. Repeat this moving your finger to a different position. Ask the patient to complete the task as quickly as they can. A patient with a cerebellar problem will show an intention tremor and past pointing (missing the target) (fig 10)

Hand tapping test-ask the patient to hold one hand steady palmer side down and with the other hand tap the dorsum (back) of the steady hand first with the palmer aspect and then with the dorsal aspect of the fingers, repetitively pronating and supinating the forearm in the process. If there is a cerebellar problem the patient will be clumsy and there will be fluctuations in both speed and amplitude of the movement. This clinical sign is called dysdiadokokinesis.

Heel-shin test-with the patient sitting or lying ask the patient to place the heel of one foot on the shin of the opposite leg just below the knee. Then ask them to run the heel along the shin to the foot and bring it back to the knee.

\section{余 Pitfall}

These tests are difficult for the normal elderly person to perform so you need to look for subtle differences between the two sides and also more than one positive sign.
A

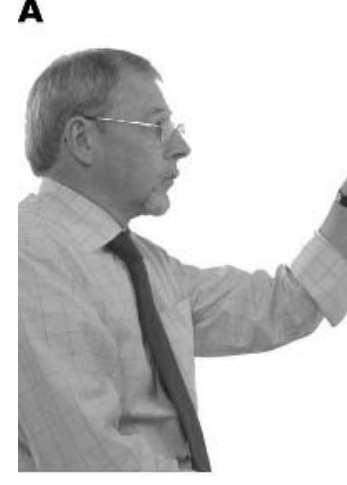

B
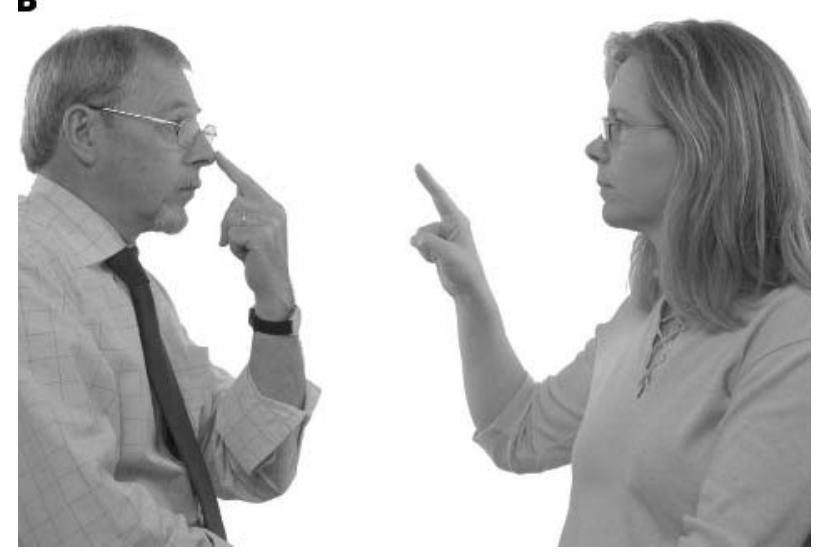

Figure 10 Finger-nose test.

Cerebellar problems will be manifest by the wandering of the heel away from the intended path.

\section{FACIAL PAIN}

Facial pain can be associated with sinusitis, dental abscesses, and many other less common conditions. Helpful questions in the history are:

- Do you have any problems with your teeth at present?

- Any trouble with your jaw when you eat?

- Do you have migrane headaches?

- Is the pain worse if you bend over?

- History of a recent upper respiratory tract infection?

Examination of the patient with facial pain should include inspection of the face for facial symmetry, erythema, blisters, and swelling. Look in the mouth for pharyngitis, condition of teeth, and any gum swelling or redness. Ask the patient to open and close the mouth, listen and feel for any jaw clicking. Palpate over the sinuses feeling for tenderness. Check the ears as described above.

\section{Sinusitis}

Sinusitis can be viral or bacterial. Sinusitis presents with facial pain, blocked nose, mucopurulent nasal discharge, and anosmia (loss of sense of smell). Referred pain may be present in teeth and ears. Evidence based treatment consists of simple analgesia/NSAID, reduction of congestion, and antibiotic treatment usually amoxycillin as first line treatment. $^{6}$

\section{Dental abscess}

Patients with a dental abscess often present with a unilateral swollen throbbing face. Treatment should be provided by a 


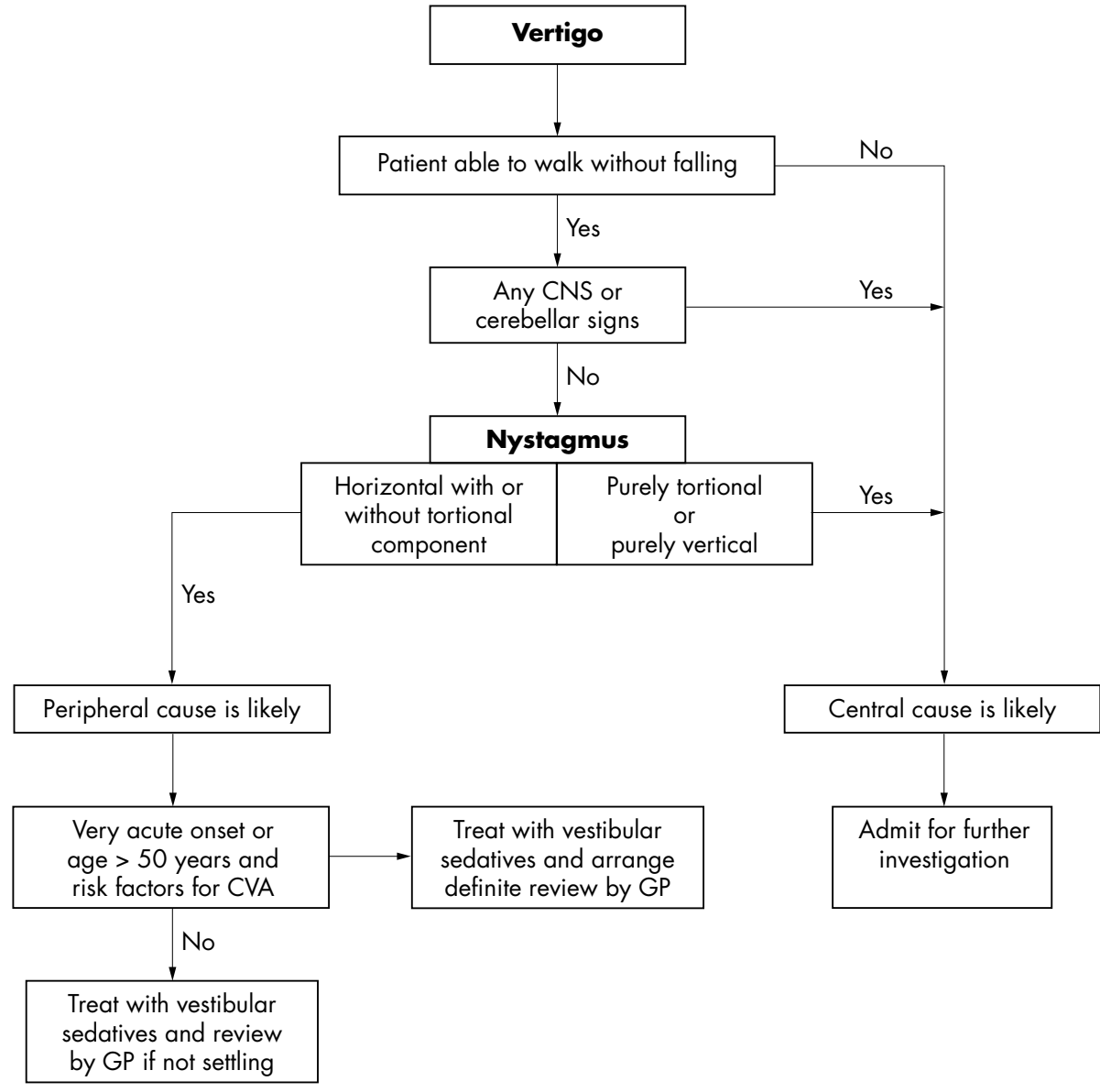

Figure 11 Vertigo flow chart.

dental practitioner as soon as possible. However, advice regarding analgesia may be given.

\section{Non-ENT causes of facial pain}

Shingles may present with unilateral facial pain before the onset of blisters. Blisters associated with shingles are always unilateral. Patients should be advised to take simple analgesia and contact their own GP within 72 hours of the onset of any blisters (see article in series on rashes). Trigeminal neuralgia can present with paroxysms of severe unilateral pain in the trigeminal nerve distribution lasting only seconds separated by pain free periods. The pain is often described as severe electric shocks. Contraction of the facial and masticatory muscles during an episode may occur. It should be treated with simple analgesia in the first instance and patients advised to see their GP.

\section{FACIAL WEAKNESS}

\section{金 Pitfall}

A cerebrovascular event is the commonest cause of facial weakness in the elderly population.

\section{Bells palsy}

Affects both sexes equally but is commonest between the ages of 10 and 40 years. It presents as a weakness of the seventh cranial (facial) nerve, the nerve that controls movement of the muscles of the face, the stapedius muscle, taste sensation of the anterior two thirds of the tongue, and lacrimal gland secretory function. The cause is often not clear, although herpes infections may be involved. Pain behind or in front of the ear may precede weakness of facial muscles by one to two days. Loss of taste (anterior two thirds of the tongue) and sensitivity to sound (hyperacusis) on the affected side may be present in more than $50 \%$ of cases. Patients often complain of headache and that their face feels stiff or pulled to one side. Objectively they have difficulty with eating and drinking and a change in facial appearance with facial droop, difficulty with facial expressions, difficulty closing one eye, difficulty with fine facial movements, drooling because of inability to control facial muscles, and dry eye secondary to being unable to close eye properly because of facial weakness. Examination shows upper and lower facial weakness, which is almost always isolated to one side of the face or occasionally to the forehead, eyelid, or mouth. Despite subjective sensory symptoms, the loss of sensation on examination is a rare and disturbing finding. If associated with a blistering rash typical of herpes zoster on ears or palate, Ramsey Hunt syndrome should be suspected (see above). Presentations outwith the typical age groups, bilateral or polyneuropathies have a higher incidence of underlying causes and need investigation. All patients should be advised to see their GP for follow up. If the patient presents out of hours they require reassurance that most cases resolve within three weeks. There is no substantial evidence at present for the use of prednisolone or aciclovir in the treatment of Bells palsy, although many people are still treated with drugs based on results of non-randomised trials. 
There are currently ongoing randomised controlled clinical trials looking at the treatment of Bells palsy.

\section{SUDDEN HEARING LOSS}

This is a rare presentation. Important points in the history: Is the hearing loss partial or complete? One side or both? Has there been any noise exposure or trauma? Examination may show wax impaction, a perforated tympanic membrane, or a normal ear. If the ear looks normal a CNS examination is mandatory to look for other signs that would point a cerebrovascular event as the cause of the hearing loss. Wax impaction is treated with softening drops and ear syringing several days later. Perforated tympanic membranes are treated as above. If a cerebrovascular event is suspected current recommendations support admission to hospital for investigation and treatment. However, if there are no other symptoms or signs the patient should be referred to the GP for assessment.

\section{TRAUMA}

Facial fractures

Maxillofacial injury is rarely life threatening unless it results in airway obstruction or severe blood loss. In both situations it is often associated with severe head and cervical spine injury. Many patients with more minor injuries will present the day after injury with swelling, bruising, closed eye, and painful jaw. These patients will require a full assessment and usually referral to an accident and emergency department with imaging facilities. The exception is a suspected fractured nose. If this is the only injury the patient should be assessed for epistaxis, septal haematoma, nasal obstruction. If none of these are present advice should be given regarding analgesia, not blowing or picking the nose, and to see their own GP for discussion regarding further management once swelling has subsided (usually around 7-10 days). If these symptoms are present referral to hospital for further assessment is required.

\section{ACKNOWLEDGEMENTS}

The authors thank Pete Driscoll and Malcolm Woollard for their helpful comments on earlier drafts of this article.

$\cdots \cdots \cdots \cdots$

Authors' affiliations

S Carter, C Laird, BASICS Scotland, Auchterarder, UK

Funding: none.

Conflicts of interest: none declared.

\section{REFERENCES}

1 American Academy of Pediatrics and American Academy of Family Physicians. Diagnosis and management of acute otitis media. Pediatrics 2004;113:1451-65.

2 SIGN. Diagnosis and management of childhood otitis media in primary care. Repart no 66. Edinburgh: SIGN, 2003. (http://www.sign.ac.uk).

3 Cates C. An evidence based approach to reducing antibiotic use in children with acute otitis media: controlled before and after study. BMJ 1999;318:715-16.

4 Little P, Gould C, Williamson I, et al. Pragmatic randomised controlled trial of two prescribing strategies for childhood acute otitis media. BMJ $2001 ; 322: 336-42$.

5 Hotson JR, Baloh RW. Acute vestibular syndrome. N Engl J Med 1998;339:680-6

6 Del Mar C, Glasziou P. Clinical Evidence 2003;issue 9:1701-11 